\title{
Object Permanence in Common Marmosets (Callithrix jacchus)
}

\author{
Natacha Mendes and Ludwig Huber \\ University of Vienna
}

\begin{abstract}
A series of 9 search tasks corresponding to the Piagetian Stages 3-6 of object permanence were administered to 11 common marmosets (Callithrix jacchus). Success rates varied strongly among tasks and marmosets, but the performances of most subjects were above chance level on the majority of tasks of visible and invisible displacements. Although up to 24 trials were administered in the tests, subjects did not improve their performance across trials. Errors were due to preferences for specific locations or boxes, simple search strategies, and attentional deficits. The performances of at least 2 subjects that achieved very high scores up to the successive invisible displacement task suggest that this species is able to represent the existence and the movements of unperceived objects.
\end{abstract}

Interactions with moving objects are crucial for the survival of many organisms. In a context in which important objects like a mate, a predator, or a prey appears, disappears, and reappears, the interactions require functional invariants. In particular, animals that move efficiently through a structured environment in three dimensions of space, like primates, must be equipped with a capacity to recognize the important object as being the same through its repeated appearances over time. If an object has disappeared, leaving no traces or perceptual cues to rely on, the search problem requires a solution on an abstract level (Dumas \& Wilkie, 1995). Such an abstract "trace" would be a representation of the absent target object in memory. Although it is known that a wide variety of animals can maintain a representation of an object that has disappeared from view, psychologists' understanding of which information is extracted from this event and their knowledge of which animals use which information to keep track of the object are far from complete.

Animals achieve different levels of abstraction, that is, different levels of understanding that objects are independent of their own action and are distinct entities in time and space (see overviews in Antinucci, 1989; Doré \& Dumas, 1987; Hauser, 2000). Piaget's (1937/1954) theory of object permanence provides a heuristic conceptual tool to investigate how animals solve such representational problems. Object permanence is the last perceptual and the first conceptual invariant: Objects are unified across the spatial and temporal discontinuities of their perceptual appearance; hence, they are constructed as independent from the subject's own per-

Natacha Mendes and Ludwig Huber, Institute of Zoology, University of Vienna, Vienna, Austria.

Financial support was provided by a scholarship from Programa de Desenvolvimento Educativo para Portugal III. This article reports portions of the research for a diploma thesis submitted by Natacha Mendes to the University of Évora, Évora, Portugal. We express many thanks to Hermann Prossinger and Michael Steurer for their help with statistical analysis and the revision of the manuscript. We are also indebted to Bernhard Voelkl for his support and encouragement during this research and to Gyula Gajdon for drawing Figure 1.

Correspondence concerning this article should be addressed to Ludwig Huber, Institute of Zoology, University of Vienna, Althanstrasse 14, 1090 Vienna, Austria. E-mail: ludwig.huber@univie.ac.at ceptions. Object permanence allows a subject to understand that objects continue to exist, even when they are no longer available for immediate perception through time and space. Because detailed descriptions of the various stages of the sensorimotor period and the tasks for which solutions involve those types of cognitive skills can be found in several reviews (Antinucci, 1989; Doré \& Dumas, 1987; Etienne, 1984; Parker \& Gibson, 1979; Uzgiris \& Hunt, 1975), a brief summary is sufficient here (see Table 1).

Piaget's theory has proved useful as a framework for comparative studies (Etienne, 1984; Pepperberg \& Funk, 1990). Piagetian procedures are effective in cross-species comparisons because the methodology involves very detailed observations (similar to ethological procedure) and the target activities can be done by nonverbal, action-oriented subjects (Funk, 1996). Furthermore, the concept of object permanence has proved to be of particular importance in nonhuman animals because of its potential ecological advantages in the lives of many species (Dumas, 1992; Etienne, 1984). The ecological relevance of the visible displacement tasks is most obvious. Animals watch prey or conspecifics moving and disappearing behind obstacles. For invisible displacement tasks, the ecological relevance is less obvious. Animals may encounter situations in which they have to make inferences about the unperceived movements of an object. To cite an example from de Blois, Novak, and Bond (1998), a male marmoset may hear the vocalizations of his female and turn his head in the direction of the noise. Meanwhile, the female continues to move in the canopies When the male looks at the location where the female was, he no longer sees her but only some conspicuously moving branches. Shortly thereafter he sees other branches moving some distance away. In this situation, it would be useful if the male understood that the female continued to move while he was not looking for her and inferred where she might be on the basis of indirect cues of her movement.

Most studies on object permanence in animals have been conducted in nonhuman primates, such as chimpanzees (Pan troglodytes: Mathieu, Bouchard, Granger, \& Herscovitch, 1976; Potì \& Spinozzi, 1994; Wood, Moriarty, Gardner, \& Gardner, 1980), gorillas (Gorilla gorilla: Natale, Antinucci, Spinozzi, \& Poti, 1986; Redshaw, 1978), orangutans (Pongo pygmeus: Call, 2001; de Blois et al., 1998), gibbons (Hylobates lar: Snyder, Birchette, \& Achenbach, 1978), rhesus monkeys (Macaca mulata: de Blois \& 
Table 1

Summary of the Stages of Object Permanence Development (After de Blois et al., 1998)

\begin{tabular}{ll}
\hline Stage & Description \\
\hline 1 and 2 & $\begin{array}{l}\text { No search for hidden objects. Infants stare at their point of disappearance. } \\
\text { Infants can retrieve a partly hidden object. }\end{array}$ \\
$4 \mathrm{a}$ & $\begin{array}{c}\text { Infants can retrieve a totally hidden object if they initiated search before the object was } \\
\text { completely hidden. } \\
\text { Infants can retrieve a totally hidden object, but they persist searching a previously rewarded } \\
\text { screen even if they saw the object disappear behind a new screen (perseveration of "A not B" } \\
\text { error). }\end{array}$ \\
$5 \mathrm{~b}$ & $\begin{array}{c}\text { Infants overcome the perseveration error, and they can find an object that was hidden behind a } \\
\text { different screen on every trial. }\end{array}$ \\
$5 \mathrm{~b}$ & $\begin{array}{l}\text { Infants can find an object that was hidden behind various screens within the same trial. } \\
6 \mathrm{a}\end{array}$ \\
$6 \mathrm{~b}$ & $\begin{array}{l}\text { Infants can find an object that was invisibly hidden behind a different screen on every trial. } \\
\text { Infants can find an object that was invisibly hidden behind various screens within the same trial. }\end{array}$
\end{tabular}

Note. From "Object Permanence in Orangutans (Pongo pygmaeus) and Squirrel Monkeys (Saimiri sciureus)," by S. T. de Blois, M. A. Novak, and M. Bond, 1998, Journal of Comparative Psychology, 112, p. 138. Copyright 1998 by the American Psychological Association. Reprinted with permission of the author.

Novak, 1994; Snyder et al., 1978; Wise, Wise, \& Zimmerman, 1974), Japanese macaques (Macaca fuscata: Natale et al., 1986), and stump-tailed macaques (Macaca arctoides: Parker, 1977). Only a small number of those examined belonged to the New World monkeys, such as cotton-top tamarins (Saguinus oedipus: Hauser, Williams, Kralik, \& Moskovitz, 2001; Santos, Ericson, \& Hauser, 1999); two Cebus species, the tufted (white-throated) capuchin (Cebus capucinus: Mathieu et al., 1976; Snyder et al., 1978) and the brown capuchin (Cebus apella: Dumas \& Brunet, 1994; Schino, Spinozzi, \& Berlinguer, 1990; Snyder et al., 1978; Spinozzi, 1989); yellow-tailed woolly monkeys (Lagothrica flavicauda: Mathieu et al., 1976); squirrel monkeys (Saimiri sciureus: de Blois et al., 1998; Vaughter, Smotherman, \& Ordy, 1972); and slender lories (Loris tardigradus: Jolly, 1964).

Both New World and Old World monkeys solve visible displacement problems. However, whether both groups are also able to comprehend invisible displacement problems is an issue of current debate. Whereas earlier studies have reported successful responses in rhesus macaques (Wise et al., 1974), squirrel monkeys (Vaughter et al., 1972), 1 stump-tailed macaque (Parker, 1977), and 1 capuchin monkey (Mathieu et al., 1976), more recent studies have drawn the competences of these species into question. With the exception of a study with rhesus monkeys (Fillion, Washburn, \& Gulledge, 1996) in which they showed the ability to infer the hidden movement in a computerized task, compelling evidence for the ability to solve the invisible displacement task is lacking. On the basis of experiments with rhesus monkeys (de Blois \& Novak, 1994) and squirrel monkeys (de Blois et al., 1998), de Blois and coauthors (de Blois \& Novak, 1994; de Blois et al., 1998) concluded that the ability to mentally represent unperceived events is shared by humans and great apes but not monkeys.

However, de Blois and coauthors (de Blois \& Novak, 1994; de Blois et al., 1998) remained cautious about adopting a dichotomous view of the distribution of cognitive skills in primates. They instead recommended that attention be given to the lesser apes to gain a more accurate understanding of the distribution and the evolution of cognitive skills in nonhuman primates. Additionally, Tomasello and Call (1997) recognized that "any general hypoth- eses about the object permanence skills of primates will remain premature until more research is done with ... marmosets and tamarins (of the New World monkeys)" (p. 42). In fact, the genus Cebus with its extraordinary manipulative abilities and its skillful foraging, which involves a detached object as a pounding tool (Antinucci \& Visalberghi, 1986; Parker \& Gibson, 1977), might not be representative of New World monkeys. Therefore, it would be interesting to explore the searching abilities in a species of the family Callithricidae, monkeys that forage mainly on fruits and plant exudates.

Common marmosets are studied on a wide scale of topics, including both cognitive and neuronal issues. We focused on social learning competencies, such as imitative learning (Bugnyar \& Huber, 1997; Voelkl \& Huber, 2000) and cooperation (Werdenich \& Huber, 2002). Studies by Bugnyar and Huber (1997), Voelkl and Huber (2000), and Werdenich and Huber (2002) incorporated artificial foraging tasks that required both manipulative and representational abilities. Neuroscientists have been interested in the relationship between simple problem solving and the prefrontal cortex. Using a number of hidden object retrieval tasks as tests of inhibition, Dias, Robbins, and Roberts (1996) provided some evidence that marmosets are able to retrieve fully occluded objects (see also Wallis, Dias, Robbins, \& Roberts, 2001). These findings, together with the fact that the subjects in our laboratory are well trained on long and close interactions with human experimenters, compelled us to look more closely into the above-mentioned abilities in common marmosets.

Therefore, the purpose of the present research was to assess as accurately as possible the level of object permanence that is displayed in the behavior of marmosets and to analyze their search activities. Object permanence is essentially assessed through standardized visible and invisible displacement tests, in which subjects have to search for and find occluded objects (Décarie, 1965; Uzgiris \& Hunt, 1975). In these tests, the standard testing procedure involves the use of a number of screens-in our study three-behind which an object that the subject will have to search for can be hidden. We administered five visible and four invisible displacement tests. 
Method

\section{Subjects}

The subjects were 11 adult common marmosets (Callithrix jacchus), of which 4 were maintained in two family groups at the Institute of Zoology, University of Vienna, Austria, and 7 were maintained in two family groups at the Konrad Lorenz Institute for Evolution and Cognition Research, Altenberg, Austria. Age, sex, rearing history, and number of offspring are given in Table 2. All marmosets were born in captivity. They were naive to the object permanence tasks at the onset of the experiment, although some had been used in social learning or cooperation experiments before (Bugnyar \& Huber, 1997; Voelkl \& Huber, 2000; Werdenich \& Huber, 2002). At the Institute of Zoology, both groups lived in identical indoor cages $(250 \times 250 \times 250 \mathrm{~cm})$ that were attached to outdoor cages of the same size. At the Konrad Lorenz Institute, both groups lived in identical indoor cages $(200 \times 350 \times 300 \mathrm{~cm})$. At both places, Vienna and Altenberg, we used an experimental cage $(135 \times 37 \times 37 \mathrm{~cm})$ to test the animals. These cages were connected with the home cage by a wire mesh tunnel, through which the marmosets could be lured individually by a piece of banana. The home cages were equipped with branches, ropes, and living plants. All marmosets were fed fruits, vegetables, monkey pellets, and protein supplements. The exception was bananas, a very attractive type of food for the common marmosets, which were never provided as part of the daily diet during the experiments. The temperature was $26-30{ }^{\circ} \mathrm{C}$ during the day and $21-23{ }^{\circ} \mathrm{C}$ at night. The humidity was approximately $70 \%-$ $80 \%$. In summer, daylight was the main source of lighting, whereas in winter, additional UV-fluorescent tubes were used to maintain a 12-hr light-dark cycle.

\section{Apparatus}

The apparatus consisted of a static wooden platform $(40 \mathrm{~cm}$ wide $\times 4$ $\mathrm{cm}$ high $\times 50 \mathrm{~cm}$ long) that was fixed to the iron mesh of the experimental cage and a thin Plexiglas board of equal surface size that could be moved on the wooden platform back and forth (see Figure 1). Three identical blue plastic boxes $(2.5 \mathrm{~cm}$ wide $\times 2.0 \mathrm{~cm}$ high $\times 2.5 \mathrm{~cm}$ long $)$ were placed on this board in a row with $10 \mathrm{~cm}$ between them. These boxes allow a small piece of very attractive food (Nestlé Trios breakfast cereals; C.P.A Cereal Partners, Vienna, Austria) to be hidden inside them. A small plastic cylinder $(1.7 \mathrm{~cm}$ high, with a $2.7-\mathrm{cm}$ diameter) was used as a container during invisible displacements. It was placed on the left, remote corner of the Plexiglas board, from the monkey's point of view.

\section{Procedure}

The marmosets received nine tests of object permanence, of which five (Tasks 1-5) involved visible displacements and four (Tasks 6-9) involved invisible displacements. Tasks $1-7$ and 9 were similar to Tasks $1-8$ of the study by de Blois and Novak (1994), who tested object permanence in rhesus monkeys (Macaca mulatta), and Task 8 was designed after the study by Gagnon and Doré (1993), who tested search behavior in invisible displacement problems in dogs (Canis familiaris).

Before the onset of the experiment, the monkeys were presented with food objects behind obstacles and under boxes to make them familiar with the necessary manipulations to recover food. These manipulations were also part of previous experiments on stimulus enhancement and social facilitation. Generally, all four family groups in Vienna and Altenberg had been confronted with learning tasks for years, of which most involved manipulations of objects and tools. Before the onset of the experiment, they were randomly assigned to two groups that differed in the order of presentation of the tests. Group 1 consisted of 2 monkeys from Vienna and 4 monkeys from Altenberg. Group 2 consisted of 2 monkeys from Vienna and 3 monkeys from Altenberg (see Table 2). In Group 1, the marmosets received the visible displacement tests first, followed by the invisible displacement tests (i.e., Tests 1-5 first and then Tests 6-9). In Group 2, the order of tests was reversed (i.e., Tests $6-9$ before Tests $1-5$ ). Counterbalancing the order of tests was based on a statement from Gagnon and Doré (1992), in which invisible displacement tests in dogs were more successful if they were preceded by visible displacement tests. If this is also true for marmosets, Group 1 should outperform Group 2.

A daily session began with the separation of 1 marmoset from the group by luring it into the experimental cage. After a short familiarization period (usually less than $5 \mathrm{~min}$ ), the test was administered in a face-to-face interaction with the experimenter (Natacha Mendes) standing behind the apparatus in front of the cage and the subject. The experimenter avoided giving any cues to the subjects as much as possible, for instance, by fixating on a point in the center of the wooden platform during the subject's choice. (The problem of experimenter's cuing in face-to-face procedures is discussed in a number of similar Piagetian experiments, like those by Gagnon \& Doré, 1992; Pepperberg \& Funk, 1990; and Pepperberg \& Kozak, 1986.)

The tests included either 9, 12, or 24 trials (see below). These numbers resulted from a compromise between statistical requirements and the avoidance of empirical learning. In all tests, the three boxes were present. The target (i.e., baited) box on the subject's right side was labeled Box A, the one in the middle was labeled Box B, and the one on the subject's left

Table 2

Characteristics of the Marmosets in Experiment 1

\begin{tabular}{lccccccc}
\hline Subject & Housed & Family & $\begin{array}{c}\text { Experimental } \\
\text { group }\end{array}$ & $\begin{array}{c}\text { Age } \\
\text { (years) }\end{array}$ & Sex & $\begin{array}{c}\text { Rearing } \\
\text { history }\end{array}$ & $\begin{array}{c}\text { No. of } \\
\text { offspring }\end{array}$ \\
\hline Pooh & VIE & 1 & 2 & 3 & M & MR & 2 \\
Theresa & VIE & 1 & 2 & 2 & F & MR & 0 \\
Shuto & VIE & 2 & 1 & 16 & M & MR & 4 \\
Vitus & VIE & 2 & 1 & 6 & M & MR & 0 \\
Dublett & ALT & 3 & 1 & 8 & F & MR & 2 \\
Diabolo & ALT & 3 & 1 & 7 & M & MR & 0 \\
Bianca & ALT & 3 & 1 & 6 & F & MR & 0 \\
Carunt & ALT & 3 & 1 & 6 & M & HR & 0 \\
Devil & ALT & 4 & 2 & 7 & M & MR & 0 \\
Mandela & ALT & 4 & 2 & 5 & F & MR & 0 \\
Niko & ALT & 4 & 2 & 5 & F & MR & 0 \\
\hline
\end{tabular}

Note. $\mathrm{VIE}=$ Vienna, Austria; $\mathrm{ALT}=$ Altenberg, Austria; $\mathrm{M}=$ male $; \mathrm{F}=$ female; $\mathrm{HR}=$ hand reared; $\mathrm{MR}=$ reared by the mother. 


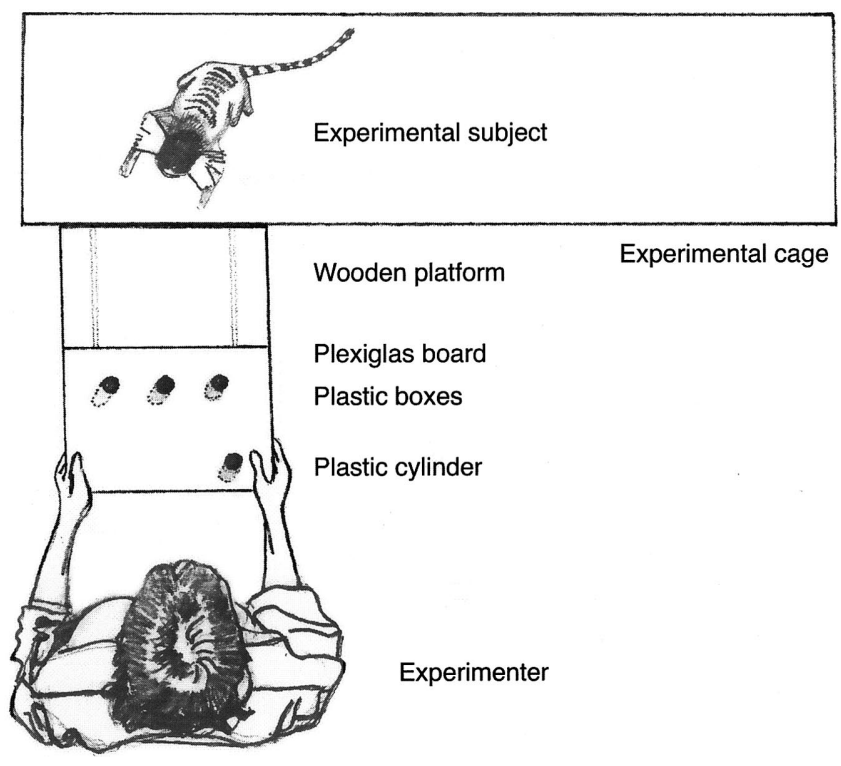

Figure 1. Schematic drawing of the experimental cage and the wooden platform with three boxes in frontal view.

side was labeled Box C. At the beginning of a trial, the experimenter waited until the subject moved to the wire mesh where the apparatus was fixed. As soon as the subject paid attention to the target object, the experimenter hid it in one of the boxes as specified below (test descriptions). The experimenter's manipulations were stopped if the subject lost attention and were continued when the subject paid attention again. A monkey's action was scored as a response if it touched a box; if it pushed the baited box, it was scored as a correct response, and if it did not, it was scored as an incorrect response (except in Test 9; see the Results section). The next trial followed immediately. In most cases, the monkeys responded within $10 \mathrm{~s}$. When subjects failed to respond after $20 \mathrm{~s}$, the trial was interrupted and restarted. The session for a monkey was stopped and continued on the next day if the subject did not make a response within 1 min. Daily sessions for each monkey lasted for approximately $5 \mathrm{~min}$, in which time up to 8 trials could be administered. Incomplete tests were completed on the following day.

Test 1: Single visible displacement. The reward was hidden in full view by the experimenter (Natacha Mendes). She first held the food reward in full view of the subject, then moved it above the board, lifted the target box with one hand, dropped it with the other hand, and finally hid it with the target box from above. Then, the Plexiglas board was moved toward the wire mesh after the manipulations were completed to allow the monkey to make a response. The subjects received 12 trials. The time interval between each trial was approximately $8 \mathrm{~s}$. Six subjects (Theresa, Pooh, Diabolo, Carunt, Dublett, and Bianca) saw the visible hiding process under Box A, and the other 5 subjects (Shuto, Vitus, Devil, Niko, and Mandela) saw the visible hiding process under Box C.

Test 2: Sequential visible displacement. Immediately after the last trial of the preceding test, the subjects saw the experimenter place the object in a different box for nine trials. Those subjects that experienced Box A as the hiding box in Test 1 now saw the food reward disappearing under Box C, and vice versa.

Test 3: Alternate single visible displacement. Each subject received 3 trials in a row in which first Box B, then Box C, and finally Box A were used as target boxes. Because each subject received eight repetitions of the BCA sequence, this test involved 24 trials.

Test 4: Successive visible displacements with two target boxes. Within a single trial, the food reward was hidden two times; it was removed from the first visited box and moved in full view of the subject into the target box before the subject could make a response. We used a predetermined order of succession of visited boxes for all subjects in a series of six trials: $\mathrm{BA}, \mathrm{AB}, \mathrm{CA}, \mathrm{AC}, \mathrm{BC}$, and $\mathrm{CB}$. These six trials were repeated four times.

Test 5: Successive visible displacement with three target boxes. Before hiding the reward in the target box, the experimenter hid and removed it from the other two boxes. The predetermined order of succession of three visited boxes in a series of six trials was the following for all subjects: $\mathrm{CBA}, \mathrm{BAC}, \mathrm{ACB}, \mathrm{CAB}, \mathrm{ABC}$, and $\mathrm{BCA}$. We repeated this sequence four times. However, the fourth repetition was altered for control reasons: Although the third box was touched and lifted, the reward was hidden under the second box visited. This control procedure determined if the marmosets searched under the last box visited by the experimenter instead of under the target box.

Test 6: Single invisible displacement. First, the reward was visibly hidden under the transport container. Then, the container was moved to the rear side (from the point of view of the subject) of the target box, which was then lifted about $1 \mathrm{~cm}$ on its rear side, and the food was pushed inside. Afterward, the transport container was shown empty to the subject and brought to its initial position. Box A was the target box for 6 subjects (Diabolo, Carunt, Dublett, Bianca, Theresa, and Pooh), and Box C was the target box for the other 5 subjects (Devil, Niko, Mandela, Shuto, and Vitus). This procedure was repeated for 12 trials.

Test 7: Sequential invisible displacement. This test followed the logic of Test 2. Immediately after the last trial of Test 6 , the target boxes were exchanged between the two groups. Nine trials were conducted with the altered target box.

Test 8: Side-by-side invisible displacement. The piece of food was put on the Plexiglas board next to the wire mesh and then pushed with the transport container (side by side) to the front side (from the monkey's point of view) of the target box. Then the experimenter continued to push the food with the transport container to the rear side (i.e., the invisible side from the monkey's point of view) of the target box, which was then lifted about $1 \mathrm{~cm}$ on the rear side, and the food was pushed inside. Then the transport container was shown to be empty to the subject and placed at its initial position. Box A was the target box for 6 subjects (Diabolo, Carunt, Dublett, Bianca, Theresa, and Pooh), and Box C was the target box for the other 5 subjects (Devil, Niko, Mandela, Shuto, and Vitus). Each subject received 24 trials. The aim of this test, created by Gagnon and Doré (1993), was to investigate the relation among food object, container, and target box.

Test 9: Successive invisible displacement with two target boxes. According to the logic of Test 4 , the food reward was hidden successively in two boxes, but this time the experimenter used the invisible displacement procedure. We used a predetermined order of succession of visited boxes for all subjects in a series of four trials: $\mathrm{AB}, \mathrm{BA}, \mathrm{CA}$, and $\mathrm{AC}$. This sequence of four trials was repeated four times. Thereafter, eight trials were presented in which all three boxes were visited. After the reward was left under the second box visited, the empty container was shown to the monkey and then moved to the third box before being placed in its initial position. Four sequences, repeated two times, were used: ABC, BAC, $\mathrm{CAB}$, and $\mathrm{ACB}$. Again, these control trials were conducted to control for the search strategy of going to the last box visited by the container.

Responses were marked as correct if the subjects pushed the target box (where the reward was hidden) and retrieved the food reward. In addition, we used a second scoring method for Test 9, after de Blois and Novak (1994; Experiment 2); responses were marked as correct if the subject made one of two choices: (a) It chose the target box directly (called direct responses), or (b) it chose first the box initially visited by the experimenter and then the target box. Correspondingly, a trial was scored as incorrect if the monkey either (a) chose the incorrect box on its first search or (b) chose the first box visited and then the incorrect box.

The subjects' responses were immediately noted on prepared data sheets. All sessions were videotaped for a post hoc detail analysis. 
Results

\section{Motivation}

All marmosets were interested in searching for the food object by reaching through the wire mesh partition and lifting one of the three boxes. Although some sessions had to be terminated and restarted on the following day because of a loss of interest, on the whole, the monkeys were equally motivated throughout the nine tests (for each subject, between four and eight sessions had to be terminated and restarted). On average, each test required less than two sessions to be administered.

\section{Test Performance}

Overall, the 11 subjects chose the correct box in 933 of a total of 1,782 trials $(52.36 \%)$. Because there was great variation in the number of successful trials across subjects and tests, we examined the influence of the two bivariate factors, location (Vienna and Altenberg) and sequence, that is, the order of presentation of the tests. A Kolmogorov-Smirnov test revealed that the data approach a normal distribution for factor location (Vienna, $Z=.557, p=$ .92; Altenberg, $Z=.766, p=.60$ ) and for factor sequence (Sequence $1, Z=.608, p=.85$; Sequence $2, Z=.642, p=.81$ ). A $2 \times 2$ (Location $\times$ Sequence) multivariate analysis of variance (MANOVA) on the total number of successful trials was conducted. The results revealed no significant effect of location, $F(1$, $95)=1.98$, or sequence, $F(1,95)=0.09$.

Because the subjects were always confronted with three possible choices, the probability of getting a correct response by chance can be assumed to be $p=1 / 3$. In Table 3, the number of correct responses of each subject in each test is shown; the number of trials and the theoretical value expected from assuming that the subjects were purely guessing are shown in Table 4 . The expectation values $(\mu)$ are derived from the binomial distribution, being the product of $k$ (the sample size, here the number of trials) and $p$ (the probability of choosing the baited box by chance). Note, for Test 9, we used here only direct responses (see the Procedure section, Test 9). The binomial test can then be applied to evaluate if the individual's score in each test was significantly higher than the score expected by chance. In particular, we asked what is the probability of obtaining values as extreme or more extreme than the observed value when we assume the data are generated by pure guessing (Siegel \& Castellan, 1988).

An analysis of the subjects' individual performances in the nine tests revealed high variation among tests and among subjects. Overall, the binomial tests used for the subjects' individual data revealed that the subjects produced very improbable scores in nearly half of all cases (in 43 of 99 cases). Cases in which the binomial tests revealed a significant deviation from chance are indicated in Table 3 by bold numbers. From inspection of Table 3 , it is evident that the subjects varied in their success rates generated in the nine object permanence tasks. However, the interindividual variation in performance is particularly high only if we take the numbers of significant scores as criterion but not if we take the sum of correct choices in all nine tests (see Table 5). Although the numbers of tests in which the individuals performed significantly above chance varied between one (Niko) and eight (Theresa), all subjects with the exception of 1 (Devil: $35.8 \%$ ) achieved significant total scores (range: $39.5 \%-67.3 \%$ ). The 2 most successful monkeys (Theresa and Pooh) produced scores of correct choices significantly higher than expected by chance in eight and seven tests, respectively. Over all tests, they chose the correct box twice as much as would be expected if they were guessing.

To compare the tests according to their difficulties for the common marmosets, we assessed two measures: the numbers of subjects that showed significant scores and the sum of correct choices from all 11 marmosets. With respect to the numbers of subjects with significant scores, Test 2 was the easiest and Tests 5 and 9 were the most difficult. In five tests (Tests 4, 5, 6, 7, and 9), less than half of the monkeys were successful. Five subjects showed extreme numbers of correct choices in Test 1, 7 in Test 2, 6 in Test 3, 4 in Test 4, 2 in Test 5, 3 in Test 6, 3 in Test 7, 6 in Test 8 , and 2 in Test 9 . Thus, we found considerable variation in the numbers of successful marmosets among tests, ranging from 2 to 9 .

Table 3

Number of Correct Choices for Each Subject in Each Test

\begin{tabular}{lcccccccrr}
\hline Subject & Test 1 & Test 2 & Test 3 & Test 4 & Test 5 & Test 6 & Test 7 & Test 8 & Test 9 \\
\hline Bianca & $\mathbf{8}$ & $\mathbf{6}$ & 10 & $\mathbf{1 1}$ & 8 & $\mathbf{1 1}$ & 1 & $\mathbf{2 2}$ & 10 \\
Carunt & $\mathbf{1 0}$ & $\mathbf{9}$ & 12 & $\mathbf{1 0}$ & 3 & 3 & 2 & $\mathbf{2 1}$ & 9 \\
Devil & 5 & 3 & $\mathbf{1 4}$ & $\mathbf{1 3}$ & 6 & 6 & 2 & 1 & 7 \\
Diabolo & 6 & $\mathbf{7}$ & $\mathbf{1 5}$ & $\mathbf{1 0}$ & 12 & 7 & 1 & $\mathbf{2 2}$ & 12 \\
Dublett & 7 & $\mathbf{7}$ & $\mathbf{1 6}$ & $\mathbf{1 1}$ & $\mathbf{1 4}$ & 7 & 3 & $\mathbf{2 2}$ & 10 \\
Mandela & 5 & 5 & $\mathbf{1 7}$ & $\mathbf{1 5}$ & 10 & 7 & $\mathbf{6}$ & 6 & 10 \\
Niko & $\mathbf{8}$ & 5 & 11 & 10 & 7 & 6 & 4 & 3 & 9 \\
Pooh & $\mathbf{1 0}$ & 2 & $\mathbf{2 0}$ & $\mathbf{1 5}$ & 10 & $\mathbf{1 1}$ & $\mathbf{6}$ & $\mathbf{1 4}$ & $\mathbf{1 9}$ \\
Shuto & 3 & $\mathbf{6}$ & 12 & $\mathbf{1 0}$ & 10 & 7 & 5 & 11 & 8 \\
Theresa & $\mathbf{1 1}$ & $\mathbf{6}$ & $\mathbf{1 7}$ & $\mathbf{1 5}$ & $\mathbf{1 3}$ & $\mathbf{1 0}$ & 1 & $\mathbf{1 7}$ & $\mathbf{1 4}$ \\
Vitus & 3 & $\mathbf{9}$ & 10 & 7 & 12 & 4 & $\mathbf{7}$ & 4 & 7 \\
& & & & & & & & & \\
$M$ & 6.9 & 5.9 & 14.0 & 11.5 & 9.5 & 7.2 & 3.5 & 13.0 & 10.4 \\
$S D$ & 2.8 & 2.2 & 3.3 & 2.6 & 3.3 & 2.6 & 2.3 & 8.4 & 3.6 \\
\hline
\end{tabular}

Note. Numbers in bold typeface indicate significant deviation from chance $(p=1 / 3)$ to higher frequencies according to the binomial distribution. In Test 9 only direct responses are used (see the text for more information). 
Table 4

Number of Trials (N), Theoretical Values Expected From Assuming That the Subjects Were Purely Guessing $(\mu)$, and Standard Deviations $(\sigma)$ for Each Test

\begin{tabular}{lrrr}
\hline Test & $N$ & $\mu$ & $\sigma$ \\
\hline 1 & 12 & 4 & 1.6 \\
2 & 9 & 3 & 1.4 \\
3 & 24 & 8 & 2.3 \\
4 & 24 & 8 & 2.3 \\
5 & 24 & 8 & 2.3 \\
6 & 12 & 4 & 1.6 \\
7 & 9 & 3 & 1.4 \\
8 & 24 & 8 & 2.3 \\
9 & 24 & 8 & 2.3 \\
\hline
\end{tabular}

However, if we measure the group performance in each test by taking the sum of correct choices from the whole group of subjects, this variation disappears. Only for Test 7 (38 correct choices out of 99 trials; $n s$ ), we cannot reject the null hypothesis (that the differences are due to chance alone). But, even in Test 4 (127 correct choices out of 264 trials; $p<.02$ ), Test 5 (105 correct choices out of 264 trials; $p<.02$ ), Test 6 (79 correct choices out of 132 trials; $p<.01$ ), and Test 9 (114 correct choices out of 264 trials; $p<$ $.01)$, the binomial tests revealed significance. In those four tests, more subjects showed scores above the chance level (10, 7, 9, and 7 subjects, respectively) than would be predicted by pure chance. With the exception of Test 7 , the common marmosets produced significant scores as a group, with small differences between tests. This fact is illustrated in Figure 2, in which the group performance in each test is shown as mean plus standard deviation of the relative scores. The highest rates were found in Tests $2(65.7 \%)$ and $4(60.2 \%)$, and the lowest rates in Tests $7(38.4 \%)$ and 5 (39.8\%). The individual variation is particularly high in Test 8 (the side-by-side invisible displacement task), ranging from 1 to 22 correct responses out of 24 trials.

To make a more general statement about the marmosets' abilities in object permanence tasks, we conducted group analyses by using one-sample $t$ tests. Although the hypothetical distribution of random guessing is not a $t$ distribution for such small numbers of trials, one-tailed $t$ tests are sometimes used in the literature (e.g., de Blois \& Novak, 1994; de Blois et al., 1998; Gagnon \& Doré, 1993) to evaluate the hypothesis that the average number of correct trials in each test is significantly higher than the average number of correct trials expected by chance. The $t$ tests revealed that the marmosets performed significantly above chance level on all visible displacement tests except Test 5: Test $1, t(10)=3.48, p<.01$; Test $2, t(10)=4.46, p<.01$; Test $3, t(10)=6.06, p<.01$; Test $4, t(10)=9.32, p<.01$; Test $5, t(10)=1.55, p=.08$. Two out of four invisible displacement tasks also did not pose serious problems to the marmosets: Test $6, t(10)=4.06, p=.01$; Test 8 , $t(10)=1.99, p=.04$. In contrast, performance on Test 7 remained at the chance level: $t(10)=0.67, p=.26$.

As mentioned above, the performance on Test 9 was analyzed in two different manners. First, we evaluated the performance by counting the number of responses that were immediately directed to the target box (direct responses). A one-sample $t$ test evaluating whether the mean of those scores is higher than the value expected by chance (8) reveals significance, $t(10)=2.20, p=.03$. Second, as suggested by de Blois and Novak (1994), two distinct responses can be scored as correct. These responses were choosing the target box directly with a probability of $1 / 3$ or choosing the first box touched by the experimenter and then selecting the baited box with a probability of $1 / 6(1 / 3 \times 1 / 2)$. Therefore, the combined probability of making a correct response on the double invisible displacement task is $1 / 2(1 / 3+1 / 6)$. A one-sample $t$ test evaluating whether the mean of those second scores of the 11 marmosets is higher than the value expected by chance (this time 12) approaches significance, $t(10)=1.72, p=.06$.

One objection that can be made to the experimental findings is that because we tested the marmosets in up to 24 trials, it becomes possible that empirical learning occurred (see, e.g., de Blois \& Novak, 1994, and Dorè \& Dumas, 1987, for discussion). With repeated exposure to the task, a monkey may simply learn that the object can be found among the hiding locations and use discriminative stimuli (e.g., the location the experimenter visited) or rules

Table 5

Comparison of Subjects' Test Performances

\begin{tabular}{lccccr}
\hline Subject & $\begin{array}{c}\text { No. of tests } \\
\text { solved }\end{array}$ & $\begin{array}{c}\text { No. of } \\
\text { sessions }\end{array}$ & $\begin{array}{c}\text { Sum of correct } \\
\text { choices }\end{array}$ & $\begin{array}{c}\text { Relative total } \\
\text { score }(\%)\end{array}$ & $p$ \\
\hline Bianca & 5 & 16 & 93 & 57.41 & $<.01$ \\
Carunt & 4 & 14 & 82 & 50.62 & $<.01$ \\
Devil & 2 & 13 & 58 & 35.80 & .28 \\
Diabolo & 4 & 13 & 95 & 58.64 & $<.01$ \\
Dublett & 5 & 16 & 81 & 62.35 & $<.01$ \\
Mandela & 3 & 13 & 64 & 50.00 & $<.01$ \\
Niko & 1 & 15 & 109 & 39.51 & .06 \\
Pooh & 7 & 15 & 78 & 67.28 & $<.01$ \\
Shuto & 2 & 17 & 66 & 48.15 & $<.01$ \\
Theresa & 8 & 17 & 14 & 65.43 & $<.01$ \\
Vitus & 2 & 14 & & 40.74 & .03 \\
\hline
\end{tabular}

Note. All subjects participated in nine tests, consisting of a total of 162 trials. Those nine tests required different numbers of sessions because sometimes sessions had to be terminated and restarted on the following day. The numbers of correct choices are given both as absolute and as relative scores. $p=$ the probability of obtaining values as extreme or more extreme than the observed value when guessing is assumed, according to the binomial distribution. In Test 9, only direct responses are used (see the text for more information). 


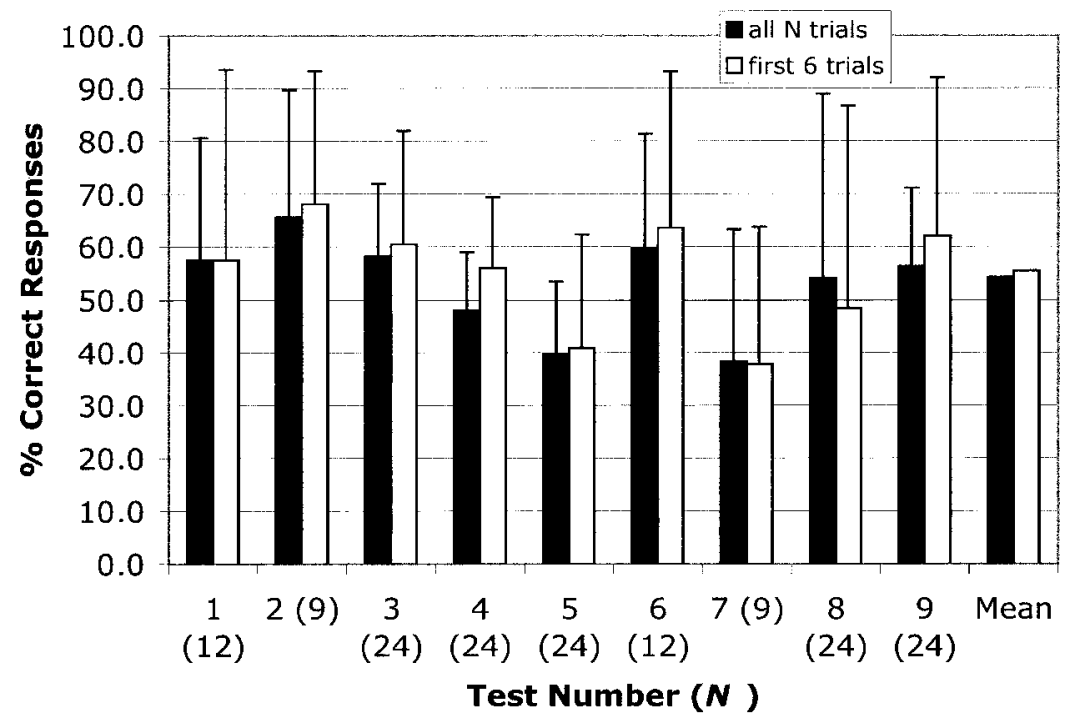

Figure 2. Mean $(+S D)$ percentage of correct responses in each of the nine presented tests. Black bars indicate performance shown in all trials of a session, whereas open bars indicate the performance shown in only the first six trials in each test.

(e.g., searching at the last location the experimenter visited) to determine where to search. If a monkey understands that an object still exists after it has disappeared, it ought to search for it spontaneously. We therefore recalculated the proportion of correct choices by focusing on the first 6 trials in each test. As is evident from inspection of the open bars in Figure 2, however, this measure hardly alters the previous findings. The marmosets were fairly constant in their choice behavior across trials, with performance being as good in the first few trials as at the end of a test. Rule learning or adaptation to the task can thus be ruled out as an explanation for good test performances.

We gained further understanding about the specific search strategies of the marmosets by analyzing the performance in the control trials of Tests 5 and 9. These controls helped to determine whether the marmosets searched under the last box visited by the experimenter. The marmosets had great difficulties solving the 6 control trials of Test 5. On average, they failed in 3.52 trials (range: 2-6). However, those failures were not restricted to the last box visited but were roughly equally distributed across the two unbaited boxes. This indicates that the subjects were confused by the experimenter visiting three instead of two boxes and that they did not adopt an alternative search strategy.

In the eight control trials in which the experimenter visited all three boxes in Test 9, roughly the same proportions of errors as in the normal trials occurred. We also compared the subjects' performance in $\mathrm{AB}$ and $\mathrm{AC}$ trials in Test 9. Some recent studies (e.g., Call, 2001) suggest that $A B$ trials are much easier than $A C$ trials. This is also true in our marmosets. Whereas the group average is 2.18 correct (direct) responses in $\mathrm{AB}$ trials, it is only 0.82 in $\mathrm{AC}$ trials. It is interesting to note that the 2 subjects with the highest scores across all tests (Pooh and Theresa) showed no difference in performance in $\mathrm{AB}$ and $\mathrm{AC}$ trials (Pooh: 4 correct responses in both $\mathrm{AB}$ and $\mathrm{AC}$ trials; Theresa: 2 correct responses in both $\mathrm{AB}$ and $\mathrm{AC}$ trials).

\section{Search Strategies in Double Displacement Tasks}

In addition to the analysis of correct choices, we investigated search strategies and preferences for specific locations. We examined the frequency with which the monkeys were engaged in different types of search in Tests 4 and 9, in which the container was successively brought into two boxes. According to de Blois and Novak (1994), a direct search consists of looking in the correct box immediately, a sequential search of looking in the box first visited by the experimenter and then in the correct box, and an irrelevant search in all other cases.

In Test 4 , we presented the sequence $\mathrm{BA}, \mathrm{AB}, \mathrm{CA}, \mathrm{AC}, \mathrm{BC}$, and $\mathrm{CB}$ four times. If a subject would have shown a total preference for one specific location (e.g., the box in the middle, Box B), it would have given 8 direct responses (in this example, the monkeys would have succeeded on $\mathrm{AB}$ and $\mathrm{CB}$ displacements), 4 sequential responses (they would have succeeded by chance on half of BA and $\mathrm{BC}$ displacements), and 12 irrelevant responses (they would have succeeded on AC and CA displacements and, by chance, on half of $\mathrm{BA}$ and $\mathrm{BC}$ displacements).

Instead of determining the exact probabilities for specific choices, we performed a chi-square test for goodness of fit with two degrees of freedom. The test investigates how well the distribution of the obtained data fit the theoretical distribution, that is, the distribution generated by a preference for one specific location. Chi-square values and statistical probabilities for Tests 4 and 9 are shown in Tables 6 and 7, respectively.

In Test 4, the obtained distribution of choices deviates significantly from the theoretical distribution for 3 subjects (Pooh, Theresa, and Mandela). These subjects gave direct responses nearly twice as often as would be expected if the subjects had been searching systematically at one specific location on their first choice. The other 8 subjects showed no significant deviation from 
Table 6

Type of Search Performed by Each Subject in Test 4

\begin{tabular}{lccccc}
\hline Subject & Direct & Sequential & Irrelevant & $\begin{array}{c}\chi^{2}(2, \\
N=24)\end{array}$ & $p$ \\
\hline Bianca & 11 & 6 & 7 & 4.21 & $n s$ \\
Carunt & 10 & 3 & 11 & 0.83 & $n s$ \\
Devil & 13 & 1 & 10 & 5.71 & $n s$ \\
Diabolo & 10 & 3 & 11 & 0.83 & $n s$ \\
Dublett & 11 & 4 & 9 & 1.88 & $n s$ \\
Mandela & 15 & 0 & 9 & 10.88 & $<.01$ \\
Niko & 10 & 2 & 12 & 1.50 & $n s$ \\
Pooh & 15 & 2 & 7 & 9.21 & .01 \\
Shuto & 10 & 6 & 8 & 2.83 & $n s$ \\
Theresa & 15 & 2 & 7 & 9.21 & .01 \\
Vitus & 7 & 3 & 14 & 0.71 & $n s$ \\
\hline
\end{tabular}

Note. The subjects underwent 24 searches. The distribution of searches among the hiding locations expected if the subjects had shown a preference for one specific location is 8 for direct searches, 4 for sequential searches, and 12 for irrelevant searches. In addition, the values of the chi-square goodness-of-fit tests assessing the degree of correspondence between the observed and expected observations in each category are shown.

the search pattern that would have resulted from a total preference for one specific location.

In Test 9, we used a predetermined order of succession of boxes for all subjects in a series of only four trials: AB, BA, CA, and AC. This sequence of four trials was repeated six times (during the last two times, the third container was lifted for control reasons). Therefore, if a subject preferred either $\mathrm{B}$ or $\mathrm{C}$, it would have shown only 6 direct responses (in $\mathrm{AB}$ or $\mathrm{AC}$ trials, respectively), 3 sequential responses $(\mathrm{B}$, in half of $\mathrm{BA}$ trials; $\mathrm{C}$, in half of $\mathrm{CA}$ trials), and 15 irrelevant responses. However, if a marmoset preferred A, it would have shown 12 direct responses (6 for BA and 6 for $\mathrm{CA}$ ), 6 sequential responses (half of $[\mathrm{AB}+\mathrm{AC}] \times 6$ ), and 6 irrelevant responses.

We therefore have to split our analysis into the hypothetical case that a subject had a preference for Box A and the other hypothetical case that a subject had a preference for either Box B or Box C. In Test 9, 7 subjects showed a pattern of searches that does not deviate significantly from a preference for one specific location. Only Pooh and Theresa directed their choices to the baited box.

\section{Discussion}

The 11 common marmosets that participated in a series of object permanence tests produced quite ambiguous results. The nine tests posed different problems to different subjects, but we cannot find any systematic trends therein. The marmosets lived at different locations, went through the tests in different orders of sequences, and were of different sex and age, but none of these factors had a significant or obvious influence on the performances on test.

The high variation in the data was most likely due to interindividual differences in the comprehension of the tasks. Therefore, without focusing on the individual level in this experiment, we cannot find a definitive answer to the question of what the upper level of object permanence in marmosets is. The very high scores of correct choices on visible and invisible displacements of at least 2 subjects suggest surprisingly high object permanence abilities in this species, but the failures of others indicate that this ability is not shared by all members of the species. In the interpretation of the data, we must therefore address two questions: (a) On the one hand, we have to consider reasons why some subjects had such great problems coping with the tasks; (b) on the other hand, we need also to discuss why some subjects achieved very high scores in those tasks and whether these performances reliably show object permanence abilities up to high Piagetian levels.

First, it is worrisome that marmosets only found the food in $57.5 \%$ of the trials in Test 1 , which should be a relatively simple test. This poor result may call into question the whole validity of the study. The bad performances might be due partly to incomplete accommodation to the experimental conditions (note that Group 1, for which Test 1 was the very first test, achieved a mean of 6.2 correct choices out of 12; whereas Group 2, for which Test 1 was the fifth test, achieved a mean of 7.8 correct choices out of 12) and to other unknown external factors. Although we mentioned reaching difficulties, we must nevertheless take into account that errors were made relatively often in choosing the center box, Box B. With regard to the validity of the whole experiment, we have to consider that the performance of most subjects was reestablished on the following test. Vitus, for instance, made only 3 correct responses out of 12 trials in Test 1 but was correct in all 9 trials of

Table 7

Type of Search Performed by Each Subject in Test 9

\begin{tabular}{|c|c|c|c|c|c|}
\hline Subject & Direct & Sequential & Irrelevant & $\begin{array}{c}\chi^{2}(2 \\
N=24)\end{array}$ & $p$ \\
\hline \multicolumn{6}{|c|}{ Preference for Box $A^{a}$} \\
\hline Bianca & 10 & 6 & 8 & 1.00 & $n s$ \\
\hline Carunt & 9 & 4 & 11 & 5.58 & $n s$ \\
\hline Devil & 7 & 4 & 13 & 10.92 & $<.01$ \\
\hline Diabolo & 12 & 5 & 7 & 0.33 & $n s$ \\
\hline Dublett & 10 & 3 & 11 & 6.00 & .05 \\
\hline Mandela & 10 & 4 & 10 & 3.67 & $n s$ \\
\hline Niko & 9 & 2 & 13 & 11.58 & $<.01$ \\
\hline Pooh & 19 & 0 & 5 & 10.25 & $<.01$ \\
\hline Shuto & 8 & 2 & 14 & 14.67 & $<.01$ \\
\hline Theresa & 14 & 1 & 9 & 6.00 & .05 \\
\hline Vitus & 7 & 3 & 14 & 14.25 & $<.01$ \\
\hline \multicolumn{6}{|c|}{ Preference for either Box B or Box $C^{b}$} \\
\hline Bianca & 10 & 6 & 8 & 8.93 & .01 \\
\hline Carunt & 9 & 4 & 11 & 2.90 & $n s$ \\
\hline Devil & 7 & 4 & 13 & 0.77 & $n s$ \\
\hline Diabolo & 12 & 5 & 7 & 11.60 & $<.01$ \\
\hline Dublett & 10 & 3 & 11 & 3.73 & $n s$ \\
\hline Mandela & 10 & 4 & 10 & 4.67 & $n s$ \\
\hline Niko & 9 & 2 & 13 & 2.10 & $n s$ \\
\hline Pooh & 19 & 0 & 5 & 37.83 & $<.01$ \\
\hline Shuto & 8 & 2 & 14 & 1.07 & $n s$ \\
\hline Theresa & 14 & 1 & 9 & 14.40 & $<.01$ \\
\hline Vitus & 7 & 3 & 14 & 0.23 & $n s$ \\
\hline
\end{tabular}

Note. The subjects underwent 24 searches. In addition, the values of the chi-square goodness-of-fit tests assessing the degree of correspondence between the observed and expected observations in each category are shown.

${ }^{a}$ The distribution of searches among the hiding locations expected if the subjects had shown a preference for one specific location is 12 for direct searches, 6 for sequential searches, and 6 for irrelevant searches. ${ }^{\mathrm{b}}$ The distribution expected if the subjects had shown a preference for one specific location is 6 for direct searches, 3 for sequential searches, and 15 for irrelevant searches. 
Test 2. Note also that de Blois and Novak (1994) reported a very similar finding with rhesus monkeys. Of 3 monkeys of their Group 2, 1 made only 1 correct response (corresponds to the chance probability) and 2 made no correct response in Test 1 (which was the same task as our Test 1). In summary, there is no reason to assume that the monkeys' poor performance in Test 1 reflects a failure to search for hidden food.

The analysis of the subjects' performances showed that there is a further reason for the overall variability. The subjects showed substantial inconsistencies across tests. This is particularly salient in those subjects that achieved a total score over all tests above $60.0 \%$ correct choices (chance level $=33.3 \%$ ). Theresa, who showed significant scores in eight tests, failed completely in Test 7 , in which she showed only one correct response. Pooh, who was significantly correct in seven tests, made only two correct choices in Test 2. Bianca, who performed at chance level in Tests 3 and 5, grasped the baited box in Test 7 only once. A very bad performance in Test 7 was also shown by Diabolo and Dublett.

The common feature of all those surprisingly bad performances of the clever subjects is that they occurred in tests in which the experimenter exchanged the position of the baited box with respect to the preceding test (Tests 2 and 7). Because in the preceding test the food was hidden 12 times under the same box, it seems as if the subjects had difficulties shifting their attention to the opposite location. Or, they might have developed a win-stay/lose-shift strategy (MacDonald, Pang, \& Gibeault, 1994), as it has been described for a number of mammalian species (Olton, Handelmann, \& Walker, 1981): Always try the response that was last rewarded, and if that is no longer rewarded, shift to another response. In fact, 3 of the 5 subjects had chosen the correct box in more than $83.0 \%$ of those tests that preceded the tests with abrupt declines (Tests 1 and 6 , respectively).

The ups and downs of the other marmosets are more difficult to interpret. Carunt, for instance, was excellent in Tests 1 and 2 but chose the correct box less than would be expected by chance in Tests 5-7. In Test 8, he again showed an excellent performance.

Preferences for specific locations or specific boxes are obvious factors that affect the object permanence behavior. Most subjects showed preferences for a specific box. Only the 2 very successful subjects, Pooh and Theresa, showed no preferences at all in the successive displacement tasks (Tests 4 and 9).

A further important requirement for appropriate search behavior in object permanence tasks is a sufficient amount of attention toward the experimenter's hiding manipulations. Because the tasks require the monkeys to figure out the relevant from the irrelevant objects and events, it makes high demands on attention processes. In successive displacement tasks, the manipulation of up to three boxes seemed to have affected the subjects' ability to visually follow the entire displacement of the object.

Finally, object permanence tasks may be interpreted as recallmemory tasks (e.g., Dumas \& Wilkie, 1995), with specific demands for the short-term memory during searching. Because subjects sometimes remained sitting for a while or turned away before reaching out to grasp a box, the time delay might have exceeded a critical length of the short-term memory.

Despite the obvious difficulties of most subjects to cope with the tasks presented in this study, the results allow us to address the question of the upper limit of object permanence in common marmosets. In the Piagetian six-stage developmental schema, the ability to solve visible displacement tasks begins in Stage 4 and is fully functional in Stage 5. Understanding invisible displacements develops during Stage 6. Whatever the reasons for the interindividual variances and for the fluctuations of performance across tests were, the results showed that all subjects demonstrated object permanence ability at Stage 4 and most of them also at Stage 5. The performance of at least 2 subjects (Pooh and Theresa) that achieved very high scores not only in most of the tests but particularly in the most critical ones (with the exception of Test 5) suggests that this species is in principle able to represent the existence and the movements of unperceived objects, thereby demonstrating object permanence at Stage 6.

Nevertheless, firm conclusions about Stage 6 abilities do require converging results from different experimental approaches. The specific procedure in this study has been used for reasons of comparison to other studies, but it might not be the most appropriate one for common marmosets. For instance, it is possible that common marmosets, like monkeys in general, have difficulties in tasks that require long and close interactions with a human experimenter (de Blois et al., 1998). Support for this conclusion comes from the fact that the best performers in this experiment are also the particularly tame and curious subjects in the groups, Pooh and Theresa.

Furthermore, to figure out if the interindividual differences are bound to the specific requirements of the present tasks or to more general cognitive differences, we should test the subjects in other tasks too. In fact, subjects Pooh and Theresa have proved to be quick learners in other experiments as well (Voelkl \& Huber, 2000). However, that the invisible displacement tasks are solved by only a few individuals should not come as a big surprise if one considers these tasks at the upper limit of common marmoset intelligence. This would lead to the conclusion that only few very intelligent or particularly experienced monkeys achieve Stage 6 abilities but that Stage 5 abilities are shared by most members of this species.

\section{References}

Antinucci, F. (1989). Systematic comparison of early sensorimotor development. In F. Antinucci (Ed.), Cognitive structure and development in nonhuman primates (pp. 67-85). Hillsdale, NJ: Erlbaum.

Antinucci, F., \& Visalberghi, E. (1986). Tool use in Cebus apella: A case study. International Journal of Primatology, 7, 349-362.

Bugnyar, T., \& Huber, L. (1997). Push or pull: An experimental study on imitation in marmosets. Animal Behaviour, 54, 817-831.

Call, J. (2001). Object permanence in orangutans (Pongo pygmaeus), chimpanzees (Pan troglodytes), and children (Homo sapiens). Journal of Comparative Psychology, 115, 159-171.

de Blois, S. T., \& Novak, M. A. (1994). Object permanence in rhesus monkeys (Macaca mulatta). Journal of Comparative Psychology, 108, 318-327.

de Blois, S. T., Novak, M. A., \& Bond, M. (1998). Object permanence in orangutans (Pongo pygmaeus) and squirrel monkeys (Saimiri sciureus). Journal of Comparative Psychology, 112, 137-152.

Décarie, T. (1965). Intelligence and affectivity in early childhood. New York: International Universities Press.

Dias, R., Robbins, T. W., \& Roberts, A. C. (1996). Primate analogue of the Wisconsin Card Sorting Test: Effects of excitotoxic lesions of the prefrontal cortex in the marmoset. Behavioral Neuroscience, 110, 872886. 
Doré, F. Y., \& Dumas, C. (1987). Psychology of animal cognition: Piagetian studies. Psychological Bulletin, 102, 219-233.

Dumas, C. (1992). Object permanence in cats (Felis catus): An ecological approach to the study of invisible displacements. Journal of Comparative Psychology, 106, 404-410.

Dumas, C., \& Brunet, C. (1994). Permanence de l'objet chez le singe capucin (Cebus apella): Etude des déplacements invisibles [Object permanence in capuchin monkeys (Cebus apella): A study on invisible displacements]. Revue Canadienne de Psychologie Expérimentale, 48, 341-357.

Dumas, C., \& Wilkie, D. M. (1995). Object permanence in ring doves (Streptopelia risoria). Journal of Comparative Psychology, 109, 142150.

Etienne, A. S. (1984). The meaning of object concept at different zoological levels. Human Development, 27, 309-320.

Fillion, C. M., Washburn, D. A., \& Gulledge, J. P. (1996). Can monkeys (Macaca mulatta) represent invisible displacement? Journal of Comparative Psychology, 110, 386-395.

Funk, M. S. (1996). Development of object permanence in the New Zealand parakeet (Cyanoramphus auriceps). Animal Learning \& Behavior, 24, 375-383.

Gagnon, S., \& Doré, F. Y. (1992). Search behavior in various breeds of adult dogs (Canis familiaris): Object permanence and olfactory cues. Journal of Comparative Psychology, 106, 58-68.

Gagnon, S., \& Doré, F. Y. (1993). Search behavior of dogs (Canis familiaris) in invisible displacement problems. Animal Learning \& Behavior, 21, 246-254.

Hauser, M. D. (2000). Wild minds: What animals really think. New York: Holt.

Hauser, M. D., Williams, T., Kralik, J. D., \& Moskovitz, D. (2001). What guides a search for food that has disappeared? Experiments on cottontop tamarins (Saguinus oedipus). Journal of Comparative Psychology, $115,140-151$.

Jolly, A. (1964). Prosimians' manipulation of simple object problems. Animal Behaviour, 12, 560-570.

MacDonald, S. E., Pang, J. C., \& Gibeault, S. (1994). Marmoset (Callithrix jacchus jacchus) spatial memory in a foraging task: Win-stay versus win-shift strategies. Journal of Comparative Psychology, 108, 328-334.

Mathieu, M., Bouchard, M. A., Granger, L., \& Herscovitch, J. (1976). Piagetian object-permanence in Cebus capucinus, Lagothrica flavicauda and Pan troglodytes. Animal Behaviour, 24, 585-588.

Natale, F., Antinucci, F., Spinozzi, G., \& Poti, P. (1986). Stage 6 object concept in nonhuman primate cognition: A comparison between gorilla (Gorilla gorilla gorilla) and Japanese macaque (Macaca fuscata). Journal of Comparative Psychology, 100, 335-339.

Olton, D. S., Handelmann, G. E., \& Walker, J. A. (1981). Spatial memory and food searching strategies. In A. C. Kamil \& T. D. Sargent (Eds.), Foraging behavior: Ecological, ethological and physiological approaches (pp. 333-345). New York: Garland.

Parker, S. T. (1977). Piaget's sensori-motor period series in an infant macaque: A model for comparing unstereotyped behavior and intelligence in human and nonhuman primates. In S. Chevalier-Skolnikoff \& F. E. Poirier (Eds.), Primate bio-social development: Biological, social and ecological determinants (pp. 43-112). New York: Garland.

Parker, S. T., \& Gibson, K. R. (1977). Object manipulation, tool use, and sensorimotor intelligence as feeding adaptations in cebus monkeys and great apes. Journal of Human Evolution, 6, 623-641.

Parker, S. T., \& Gibson, K. R. (1979). A developmental model for the evolution of language and intelligence in early hominids. Behavioral and Brain Sciences, 2, 367-408.

Pepperberg, I. M., \& Funk, M. S. (1990). Object permanence in four species of psittacine birds: An African grey parrot (Psittacus erithacus), an Illiger mini macaw (Ara maracana), a parakeet (Melopsittacus undulatus) and a cockatiel (Nymphicus hollandicus). Animal Learning \& Behavior, 18, 97-108.

Pepperberg, I. M., \& Kozak, F. A. (1986). Object permanence in the African grey parrot (Psittacus erithacus). Animal Learning \& Behavior, $14,322-330$.

Piaget, J. (1954). The construction of reality in the child. Oxford, England: Basic Books. (Original work published 1937)

Potì, P., \& Spinozzi, G. (1994). Early sensorimotor development in chimpanzees (Pan troglodytes). Journal of Comparative Psychology, 108, 93-103.

Redshaw, M. (1978). Cognitive development in human and gorilla infants. Journal of Human Evolution, 7, 133-141.

Santos, L. R., Ericson, B., \& Hauser, M. D. (1999). Constraints on problem solving and inhibition: Object retrieval in cotton-top tamarins. Journal of Comparative Psychology, 113, 186-193.

Schino, G., Spinozzi, G., \& Berlinguer, L. (1990). Object concept and mental representation in Cebus apella and Macaca fasciularis. Primates, $31,537-544$

Siegel, S., \& Castellan, N. J. J. (1988). Nonparametric statistics for the behavioral sciences. New York: McGraw-Hill.

Snyder, D. R., Birchette, L. M., \& Achenbach, T. M. (1978). A comparison of developmentally progressive intellectual skills between Hylobates lar, Cebus apella and Macaca mulatta. In D. J. Chivers \& J. Herbert (Eds.), Recent advances in primatology (Vol. 3, pp. 945-948). New York: Academic Press.

Spinozzi, G. (1989). Early sensoriomotor development in Cebus (Cebus apella). In F. Antinucci (Ed.), Cognitive structure and development in nonhuman primates (pp. 55-66). Hillsdale, NJ: Erlbaum.

Tomasello, M., \& Call, J. (1997). Primate cognition. New York: Oxford University Press.

Uzgiris, I. C., \& Hunt, J. (1975). Assessment of infancy: Ordinal scales of psychological development. Champaign: University of Illinois Press.

Vaughter, R. M., Smotherman, W., \& Ordy, J. M. (1972). Development of object permanence in the infant squirrel monkey. Developmental Psychology, 7, 34-38.

Voelkl, B., \& Huber, L. (2000). True imitation in marmosets. Animal Behaviour, 60, 195-202.

Wallis, J. D., Dias, R., Robbins, T. W., \& Roberts, A. C. (2001). Dissociable contributions of the orbitofrontal and lateral prefrontal cortex of the marmoset to performance on a detour reaching task. European Journal of Neuroscience, 13, 1797-1808.

Werdenich, D., \& Huber, L. (2002). Social factors determine cooperation in marmosets. Animal Behaviour, 64, 769-779.

Wise, K. L., Wise, L. A., \& Zimmerman, R. R. (1974). Piagetian object permanence in the infant rhesus monkey. Developmental Psychology, 10, 429-437.

Wood, S., Moriarty, K. M., Gardner, B. T., \& Gardner, R. A. (1980). Object permanence in child and chimpanzee. Animal Learning \& Behavior, 8, 3-9.

Received May 7, 2003

Revision received July 16, 2003

Accepted July 19, 2003 